\title{
Demonstration by a nested PCR for Mycoplasma pneumoniae that $M$. pneumoniae load in the throat is higher in patients hospitalised for $M$. pneumoniae infection than in non-hospitalised subjects
}

\author{
J. WENDELIEN DORIGO-ZETSMA, SEBASTIAN A. J. ZAAT, ALDWIN J. M. VRIESEMA and \\ JACOB DANKERT
}

Department of Medical Microbiology, Academic Medical Center, Meibergdreef 91105 AZ Amsterdam, The Netherlands

\begin{abstract}
A nested PCR protocol to detect Mycoplasma pneumoniae DNA in throat specimens was developed. An amplification control (AC) template, which is amplified by the same primers as the $M$. pneumoniae target sequence, was constructed. The assay allowed highly specific and sensitive detection of $M$. pneumoniae DNA. In all, 305 throat samples, 62 from hospitalised patients and 243 from non-hospitalised subjects, were analysed by the nested PCR. Inhibition of the PCR was observed in $20 \%$ of the samples, but was abolished after a 1 in 10 dilution. Throat samples from $5(8 \%)$ of the hospitalised patients and from $7(3 \%)$ of the non-hospitalised subjects were positive for $M$. pneumoniae DNA. To investigate the relationship between $M$. pneumoniae load and the severity of disease, the $M$. pneumoniae load in 10 throat samples from $M$. pneumoniae-positive subjects was assessed semi-quantitatively by application of the nested PCR to a series of limiting dilutions of nucleic acid extracted from these throat samples. The calculated $M$. pneumoniae load varied from 20 to $3830 \mathrm{cfu} / \mathrm{ml}$ of throat sample. The mean $M$. pneumoniae load in samples from the hospitalised patients was significantly higher than that in samples from the non-hospitalised subjects. The nested PCR is a useful tool to detect $M$. pneumoniae DNA in the throat and to study the relationship between the load of $M$. pneumoniae in throat samples and severity of disease due to $M$. pneumoniae infection.
\end{abstract}

\section{Introduction}

Mycoplasma pneumoniae is a common cause of upper and lower respiratory tract infections in man. The majority of these infections are relatively mild, but serious disease like pneumonia can require hospitalisation. Complications of the primary infection, e.g., neurological and cardiovascular complications, can also occur [1-3]. M. pneumoniae infection is diagnosed

Received 30 Dec. 1998; revised version accepted 17 May 1999.

Corresponding author: Dr J.W. Dorigo-Zetsma. Present address: Diagnostic Laboratory for Infectious Diseases and Perinatal Screening (LIS), National Institute of Public Health and the Environment, Antonie van Leeuwenhoeklaan 9, PO Box 1, 3720 BA Bilthoven, The Netherlands (e-mail: Wendelien.Dorigo@rivm.nl). routinely by serological methods or by culture, or by both. Because these diagnostic approaches have disadvantages, such as repeated blood sampling to perform reliable serology [4] and the slow growth of $M$. pneumoniae in culture, molecular diagnostic techniques have been applied to the laboratory diagnosis of $M$. pneumoniae infection. Both DNA hybridisation techniques [5-8] and the PCR [5,9-14] have been used.

The clinical significance of a positive PCR result for $M$. pneumoniae in throat specimens obtained from patients can be obscured by the fact that $M$. pneumoniae can persist in the throat after symptomatic infection [15] and even after antibiotic treatment [8]. As a relationship between high levels of $M$. pneumoniae in the throat and clinically significant respiratory tract infection has been observed $[8,13]$, molecular diagnostic methods that allow detection of $M$. pneu- 
moniae and estimation of its load are required. Therefore, a nested PCR assay for rapid and sensitive detection of $M$. pneumoniae in throat specimens was developed. The PCR assay was designed with an amplification control (AC) template to verify amplification from clinical specimens. The method was applied to the laboratory diagnosis of $M$. pneumoniae infection in a group of hospitalised patients, in patients who attended their general practitioner (GP) and in household contacts of patients with a positive PCR for $M$. pneumoniae. Subsequently, the $M$. pneumoniae load in the severely ill hospitalised patients and in the patients with relatively mild or no symptoms was estimated by applying the nested PCR to a series of limiting dilutions of nucleic acid isolated from throat swabs.

\section{Materials and methods}

\section{Patients and throat sample preparation for nested PCR}

Samples were obtained from patients admitted to hospital with community-acquired pneumonia, from patients visiting their GP because of a respiratory tract infection and from household contacts of $M$. pneumoniae DNA-positive patients in the hospitalised and nonhospitalised groups. Between Feb. 1997 and Aug. 1997 a total of 302 throat samples was collected from 62 hospitalised patients, 208 non-hospitalised patients and 32 household contacts. A further three follow-up throat samples were collected from asymptomatic, but $M$. pneumoniae-positive, household contacts 3-4 weeks after the first sample. Patients who had to be hospitalised because of community-acquired respiratory tract infection were defined as more severely ill than non-hospitalised patients. Hospital nursing staff collected the throat swabs from the hospitalised patients and the GPs or their staff collected the throat swabs from the non-hospitalised patients. In the hospital as well as at the GP practices patients were sampled according to a standard protocol. Throat samples were collected on cotton-tipped swabs, which subsequently were agitated in $2 \mathrm{ml}$ of transport medium (PPLObroth, yeast extract $10 \%$, unheated horse serum $20 \%$, glucose $0.5 \%$, phenol red $0.002 \%$ and penicillin $1000 \mathrm{U} / \mathrm{ml}$ ). A $200-\mu 1$ sample of the transport medium in which the throat swab had been agitated was centrifuged at $12000 \mathrm{~g}$ for $30 \mathrm{~min}$. The remaining $1.8 \mathrm{ml}$ was stored at $-70^{\circ} \mathrm{C}$. Pellets were resuspended in $100 \mu \mathrm{l}$ of lysis buffer $(50 \mathrm{mM} \mathrm{KCl}, 10 \mathrm{mM}$ Tris- $\mathrm{HCl}$,
pH 8.3, NP40 0.45\%, Tween $200.45 \%$, proteinase K $10 \mathrm{mg} / \mathrm{ml}$ ) (Boehringer Mannheim GmbH, Mannheim, Germany) and incubated at $50^{\circ} \mathrm{C}$ for $2 \mathrm{~h}$. Subsequently, samples were heated at $95^{\circ} \mathrm{C}$ for $15 \mathrm{~min}$ to inactivate proteinase $\mathrm{K}$. Ten $\mu \mathrm{l}$ of the lysed sample were used as template in the first reaction of the nested PCR (see below). The proteinase $\mathrm{K}$ protocol was used because the detection limits of $M$. pneumoniae DNA in throat swab specimens prepared by proteinase $\mathrm{K}$ lysis or by the more elaborate DNA extraction protocol of Boom et al. [16] were identical [17].

\section{Nested PCR protocol}

A nested PCR for amplification of $M$. pneumoniae DNA was designed, based on the P1 cytadhesin gene PCR of Ursi et al. [18]. Primers P1-1 and P1-6 (Table 1), which amplify a 272-bp fragment of the P1 gene, were used in the first PCR [19]. The nested primers P12 and P1-3 (Table 1) used in the second PCR amplify a 133-bp fragment. Primers were obtained from Perkin Elmer Applied Biosystems (Nieuwerkerk a/d IJssel, The Netherlands). Amplifications were performed in a final volume of $50 \mu \mathrm{l}$ containing $10 \mathrm{mM}$ Tris- $\mathrm{HCl}$ ( $\mathrm{pH} \mathrm{8.3),} 50 \mathrm{mM} \mathrm{KCl}, 1.5 \mathrm{mM} \mathrm{MgCl}_{2}, 200 \mathrm{mM}$ of each deoxynucleoside triphosphate (Perkin Elmer), 20 pmol of each primer, $1 \mathrm{U}$ AmpliTaq DNA polymerase (Roche Molecular Systems, Branchburg, NJ, USA), $2 \mu 1$ AC template and $10 \mu \mathrm{l}$ of sample. Amplification was performed in a 9600 Thermocycler (Perkin Elmer) with a programme of $5 \mathrm{~min}$ at $95^{\circ} \mathrm{C}$, followed by 30 cycles of $15 \mathrm{~s}$ at $95^{\circ} \mathrm{C}, 1 \mathrm{~min}$ at $65^{\circ} \mathrm{C}, 1.5 \mathrm{~min}$ at $72^{\circ} \mathrm{C}$ and a final step of $10 \mathrm{~min}$ at $72^{\circ} \mathrm{C}$. One $\mu 1$ of the first PCR product was added to the reaction mixture of the second PCR. The second PCR was performed under the same conditions as the first PCR in a 20-cycle procedure. Ten $\mu \mathrm{l}$ of the reaction products were analysed on Metaphor agarose (FMC Bioproducts, Rockland, USA) $2 \%$ gels containing ethidium bromide $0.5 \mu \mathrm{g} / \mathrm{ml}$ for visualisation of amplicons by UV transillumination.

\section{Prevention of PCR contamination}

Preparation of the patient samples by lysis or DNA extraction and preparation of the PCR mixtures were performed in safety hoods equipped with UV germicidal lamps, in separate dedicated positive pressure laboratories $(>10 \mathrm{~Pa})$ with lock-gates. Addition of the patient samples to the PCR reaction mixtures was

Table 1. Primers used for the detection of $M$. pneumoniae DNA

\begin{tabular}{|c|c|c|c|}
\hline $\begin{array}{l}\text { Primer } \\
\text { name }\end{array}$ & Nucleotide sequence & $\begin{array}{l}\text { Corresponding region } \\
\text { of the P1 gene* }\end{array}$ & $\begin{array}{l}\text { Reference } \\
\text { no. }\end{array}$ \\
\hline P1-1 & 5'-GCCACCCTCGGGGGCAGTCAG-3' & $2757-2777$ & 18 \\
\hline P1-6 & 5'-ATCGCATTGCCGTCCTGCGTGG-3' & $3028-3007$ & This study \\
\hline P1-2 & 5'-CTGAACGGGGGCGGGGTGAAGG-3' & $2834-2855$ & 10 \\
\hline P1-3 & 5'-GAGTCGGGATTCCCCGCGGAGG-3' & $2965-2944$ & 18 \\
\hline
\end{tabular}

${ }^{*}$ Nucleotide position within the P1 gene sequence [19] (Genbank accession number M 18639). 
performed in a third room. To check for crosscontamination of samples and for amplicon contamination during the procedure, negative controls were included after every fourth patient sample from the start of the preparation procedure. These negative controls consisted of transport medium without patient material and were processed in the same way as the patient samples. Pipetting of amplicons from the first into the second PCR reaction mixture was performed in a fourth room. During this part of the procedure gloves were changed after pipetting each sample. Finally, gel electrophoresis of the amplification products was performed in a fifth laboratory, located in a different building.

\section{AC template for nested PCR}

To enable detection of PCR inhibition in clinical specimens, an AC template was constructed for the nested PCR. The AC DNA template was a PCR product of the P1 gene into which had been inserted, between the sites recognised by the internal nested primers, a 210-bp sequence from the lacZ gene of Escherichia coli. As this target generates a longer PCR product than the naturally occurring template, it can be used to spike clinical specimens for PCR and produce a positive control band which can be distinguished easily from the natural product on the basis of size. The absence of the AC product in a spiked reaction thus signals the likely presence of PCR inhibitors in the clinical sample. Extended primers designated P1-1* (5'-GCCGGAATTCGCCACCCTCGGGGGCAGTCAG $\left.-3^{\prime}\right)$ and P1-6* (5'-GGTGCTGCAGATCGCATTGCC GTCCTGCGTGG-3') containing terminal EcoRI and Pst I restriction sites, respectively, were used to amplify a 292-bp P1 gene fragment from DNA of $M$. pneumoniae strain PI 1428. The reaction was performed with $1 \mathrm{ng}$ of purified genomic DNA [16] as template and the PCR procedure was performed as described for the P1-1/P1-6 PCR. The PCR fragment was digested with EcoRI and Pst I (Boehringer Mannheim), purified from a Metaphor agarose 2\% gel with QiaEx (Qiagen GmbH, Hilden, Germany) and ligated to EcoRI- and Pst I-digested plasmid pUC18Sfi [20]. Enzymic reactions and transformation of $E$. coli were performed according to standard molecular biological procedures [21]. The ligation mixture was used to transform E. coli JM101 competent cells. From ampicillin-resistant transformants, plasmids were isolated with the Qiagen plasmid mini kit (Qiagen). One plasmid isolate, pMM1, containing the EcoRI-Pst I gene fragment, was used in further experiments. A fragment of the $E$. coli lacZ gene (bp 815-1018) was amplified from plasmid pMP220 [22] with KpnItailed primers PMM2lac1 (5'-TCATGGTACCCGCCT TTCGGCGGTGAAATTATCG-3') and PMM2lac2 (5' - AGTAGGTACCCATTTTCAATCCGCACCTCGCG G-3'). Amplification was performed in a programme of 30 cycles of $15 \mathrm{~s}$ at $95^{\circ} \mathrm{C}, 1 \mathrm{~min}$ at $55^{\circ} \mathrm{C}, 1.5 \mathrm{~min}$ at $72^{\circ} \mathrm{C}$ and a final step of $10 \mathrm{~min}$ at $72^{\circ} \mathrm{C}$. The fragment was digested with $K p n \mathrm{I}$, purified from Metaphor agarose $2 \%$ gel with QiaEx and ligated to KpnIdigested plasmid pMM1. The size of the inserted lacZ fragment, including mucleotides of the added Kpn I sites, was $210 \mathrm{bp}$. After transformation of E. coli JM101, plasmids from ampicillin-resistant colonies were isolated and analysed by restriction digestion for the presence of the lacZ fragment. One plasmid containing the proper insertion, pMM2, was selected for further experimentation. Primers P1-1 and P1-6 amplified a 482-bp fragment from plasmid pMM2. This fragment was purified from an agarose gel with QiaEx. The minimum concentration of this AC construct required to generate a visible 482-bp band in gel after amplification was determined.

\section{M. pneumoniae strains and growth conditions}

M. pneumoniae strains MAC (ATCC 15492) and PI1428 (ATCC 29085) were cultured in modified Chanock broth [23] and in SP4 broth [24] at $36^{\circ} \mathrm{C}$ in a humidified atmosphere of $\mathrm{CO}_{2} 5 \%$ in air until colour change occurred (after 6 and 7 days for strains MAC and PI-1428, respectively). To determine bacterial density, 10-fold serial dilutions of the mycoplasma suspensions were made in Chanock broth and SP4 broth, respectively, and $100-\mu \mathrm{l}$ samples were plated on modified Chanock agar and SP4 agar in triplicate. Plates were incubated at $36^{\circ} \mathrm{C}$ in $\mathrm{CO}_{2} 5 \%$ in air for 724 days. Colonies were counted by examining the plates with an inverted microscope at $40 \times$ magnification. At the time of colour change, cultures of $M$. pneumoniae strain MAC and PI 1428 contained $7 \times 10^{4} \mathrm{cfu} / \mathrm{ml}$ and $1.5 \times 10^{6} \mathrm{cfu} / \mathrm{ml}$, respectively.

\section{Specificity and detection limit of the nested PCR}

DNA from clinical isolates of the following bacteria was used to test the specificity of the nested PCR: $M$. orale, M. hominis, $M$. salivarium, $M$. fermentans and M. genitalium, Chlamydia pneumoniae, Legionella pneumophila, viridans streptococci, Staphylococcus aureus, Haemophilus influenzae, Neisseria meningitidis, Moraxella catarrhalis, Streptococcus pneumoniae, E. coli and Klebsiella pneumoniae. In addition, the nested PCR was applied to throat swab specimens obtained from 10 volunteers, who had been without respiratory illness 1 month before and after throat swab sampling.

To assess the detection limit of the nested PCR, throat samples from healthy volunteers were spiked with $M$. pneumoniae strain MAC $\left(7 \times 10^{4} \mathrm{cfu} / \mathrm{ml}\right)$ or strain PI $1428\left(1.5 \times 10^{6} \mathrm{cfu} / \mathrm{ml}\right)$. These spiked samples were serially diluted in 10-fold steps in transport medium, subjected to proteinase $\mathrm{K}$ lysis and the lysates were analysed in the nested PCR. 


\section{Semi-quantitative assessment of $M$. pneumoniae load in throat samples}

There was sufficient material available to assess the $M$. pneumoniae load in $10 \mathrm{M}$. pneumoniae PCR-positive throat samples. To enable standardisation of the template input for the semi-quantitative PCR, total nucleic acid (NA) from $500 \mu \mathrm{l}$ of the throat samples was extracted [16] and the concentration of purified NA was determined spectrophotometrically. NA concentrations were adjusted to $6 \mu \mathrm{g} / \mathrm{ml}$ for all samples; $10 \mu 1$ of these adjusted samples and of 10 -fold serial dilutions of the samples were used as input in the PCR. The highest 10-fold dilution which was PCR-positive was assumed to contain a number of cfu equal to the detection limit of the PCR. From this dilution, the number of $M$. pneumoniae $\mathrm{cfu} / \mu \mathrm{g}$ of throat sample NA was calculated. Based on this value and the recorded concentration of NA in the original throat sample extract, the number of $\mathrm{cfu} / \mathrm{ml}$ of throat sample was calculated.

\section{Statistical analysis}

Values of $M$. pneumoniae $\mathrm{cfu}\left(\log _{10}\right) / \mathrm{ml}$ in throat samples from hospitalised patients and non-hospitalised subjects were compared with the Student's $t$ test.

\section{Results \\ Primer specificity and detection limit of the nested PCR protocol in simulated clinical specimens}

Specificity of the primer sets for M. pneumoniae DNA was confirmed by performing the nested PCR on various Mycoplasma spp., C. pneumoniae, L. pneumophila and on eight other bacteria commonly residing in the nasopharynx. The nested PCR was also performed on lysates of throat swab specimens from 10 healthy volunteers. None of these controls showed the $M$. pneumoniae-specific signal (data not shown). The detection limit in the lysates of simulated clinical specimens corresponded to 0.6 and $1.3 \mathrm{cfu}$ of strains MAC and PI-1428, respectively. These detection levels were highly reproducible: the detection was identical in five independent experiments performed at different times. Based on these data, the average detection limit was defined as $1 \mathrm{cfu}$ of $M$. pneumoniae.

\section{Amplification control}

A final AC concentration of $0.07 \mathrm{fg} / \mu 1$ still allowed detectable amplification in the absence of $M$. pneumoniae DNA. In the presence of $M$. pneumoniae, this concentration of AC did not interfere with PCR detection of $M$. pneumoniae DNA in simulated clinical specimens (Fig. 1), i.e., the M. pneumoniae-specific signal was observed in the same dilutions in the presence or absence of the AC.

\section{Patients with M. pneumoniae-positive throat samples}

For a 6-month period, from Feb. until Aug. 1997, 305 throat samples were analysed by the nested $M$. pneumoniae PCR. No PCR contamination was observed in negative controls included after each fourth patient sample. Inhibition of the PCR, as detected by the absence of the 482-bp band of the AC, occurred in $20 \%$ of the samples. After 1 in 10 dilution of these samples, no inhibition of the AC amplification was observed. Throat samples gave positive results for $M$. pneumoniae in $5(8 \%)$ of the 62 hospitalised patients and in $7(3 \%)$ of the 240 non-hospitalised subjects. In the non-hospitalised group, 3 (1.4\%) M. pneumoniaepositive patients were identified among the 208 GP patients and $4(13 \%)$ among the 32 household contacts of the eight $M$. pneumoniae-positive patients. Of the four $M$. pneumoniae-positive contacts, one subject had symptoms of a respiratory tract infection and three were asymptomatic before and at the time of sampling. Two of them remained asymptomatic and follow-up throat samples, taken 4 weeks after the first sample, were negative. The third apparently was in the incubation period of a $M$. pneumoniae infection, as he developed a respiratory tract infection 2 weeks after the first sample was taken. His follow-up throat sample, taken 3 weeks after the first sample, was still positive. The mean age of the hospitalised $M$. pneumoniaepositive patients was 8 (range 3-14) years and of the non-hospitalised $M$. pneumoniae-positive subjects 11 (range 2-26) years. The mean interval between occurrence of disease and sampling for the five hospitalised patients was 6 (range 5-11) days and for the three non-hospitalised patients and the two symptomatic household contacts this was 5 (range 28) days.

\section{Semi-quantitative assessment of $M$. pneumoniae load in throat samples}

The M. pneumoniae load was assessed semi-quantitatively in $10 \mathrm{M}$. pneumoniae-positive throat samples, five from five hospitalised patients and five from four non-hospitalised subjects, the latter comprising two GP patients and two household contacts. Two samples were analysed from one household contact. The first sample was obtained when this subject was asymptomatic and a follow-up sample was obtained 3 weeks later when he had mild symptoms of respiratory infection. The second household contact was asymptomatic. The NA contents of throat sample varied between 1.0 and $2.3 \mu \mathrm{g} / \mathrm{ml}$ (mean 1.6). The nested PCR produced easily interpretable all-or-none signals in the dilution series. The highest dilutions that showed the M. pneumoniaespecific PCR signal (Fig. 2) were used to calculate the $M$. pneumoniae load, based on the established average detection limit of $1 \mathrm{cfu}$. The calculated $M$. pneumoniae load varied from 20 to $3830 \mathrm{cfu} / \mathrm{ml}$ of throat sample. The mean $M$. pneumoniae load in the hospitalised 

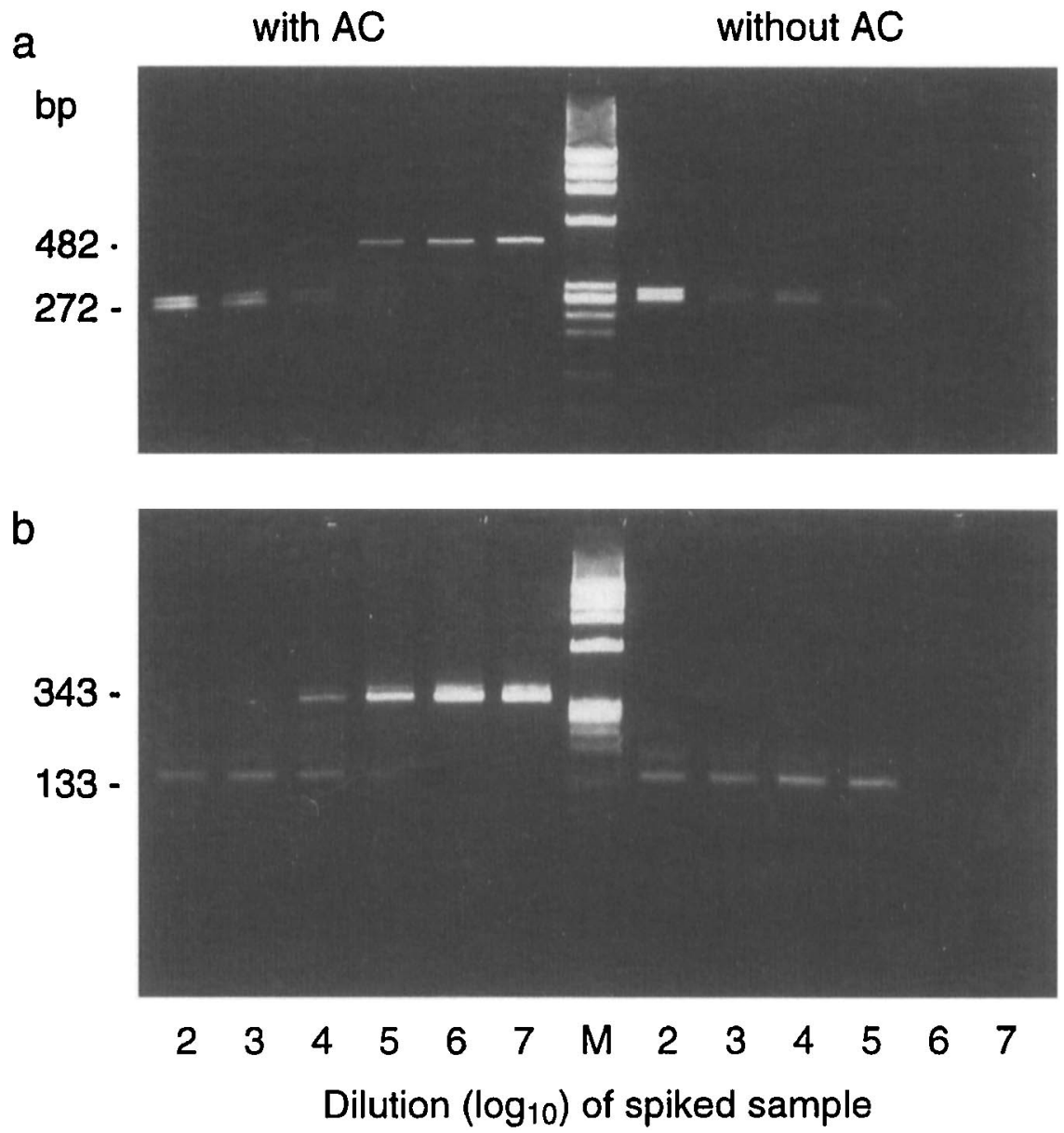

Fig. 1. Amplification of $M$. pneumoniae DNA in the presence and absence of AC. (a) First PCR: M. pneumoniae target, $272 \mathrm{bp}$; AC, $482 \mathrm{bp}$. (b) Second PCR: $M$. pneumoniae target, $133 \mathrm{bp}$; AC, $343 \mathrm{bp}$. Left side: PCR products of limiting 10 -fold dilution series of a lysate of a throat swab specimen seeded with $M$. pneumoniae strain MAC $\left(7 \times 10^{4} \mathrm{cfu} / \mathrm{ml}\right)$. A final AC concentration of $0.07 \mathrm{fg} / \mu \mathrm{l}$ was added to all samples. Right side: PCR products of samples without AC, but otherwise identical to the left side. M, DNA mol.wt marker IX (Boehringer Mannheim).

patients was $2500 \mathrm{cfu} / \mathrm{ml}$ of throat sample, whereas the mean $M$. pneumoniae load in the non-hospitalised group was $100 \mathrm{cfu} / \mathrm{ml}$ of throat sample (Fig. 3). The $M$. pneumoniae load in the first and second sample of the person who was asymptomatic at first sampling but became symptomatic after 2 weeks was only slightly different $(260$ and $170 \mathrm{cfu} / \mathrm{ml}$ of throat sample, respectively). The difference in $\mathrm{cfu}\left(\log _{10}\right) / \mathrm{ml}$ between the hospitalised and non-hospitalised group was 1.5 (95\% CI 0.77-2.24) $(\mathrm{p}=0.0016)$.

\section{Discussion}

In the present study a nested PCR for $M$. pneumoniae, with the target sequence in the P1 cytadhesin gene, was developed. This PCR protocol was applied to proteinase $\mathrm{K}$ lysates of throat swab specimens, to assess rapid laboratory diagnosis of $M$. pneumoniae infection. Sensitivity of detection of $M$. pneumoniae by PCR depends on the sample preparation method [13], the primer pairs used $[10,14,25]$, the type of clinical specimen on which the PCR is performed [26], the use of genuine versus simulated clinical specimens [25] and signal enhancement by hybridisation after PCR [27]. Detection limits of $1.5-50 \mathrm{cfu}, 10-100$ colour changing units (ccu) and 5-50 fg of template DNA have been reported $[3,13,14,28]$. This nested PCR allowed detection of $1 \mathrm{cfu}$ of $M$. pneumoniae in proteinase $\mathrm{K}$ lysates of simulated $M$. pneumoniaepositive throat samples. In addition to a high sensitivity, the nested PCR protocol has the advantage of direct confirmation of the identity of the first PCR product, without the need for a time-consuming and labour-intensive hybridisation step. The risk of carryover contamination associated with nested PCR was minimised by performing all steps of the procedure in separate rooms. Negative controls included after each fourth test sample were PCR negative in all cases, indicating that contamination was effectively prevented.

Clinical samples may contain compounds that inhibit Taq polymerase $[18,26]$; many PCR protocols for detection of $M$. pneumoniae DNA lack an amplification control (AC) to check for such inhibition $[9,11,27]$. In the present study an $\mathrm{AC}$ template was constructed for 

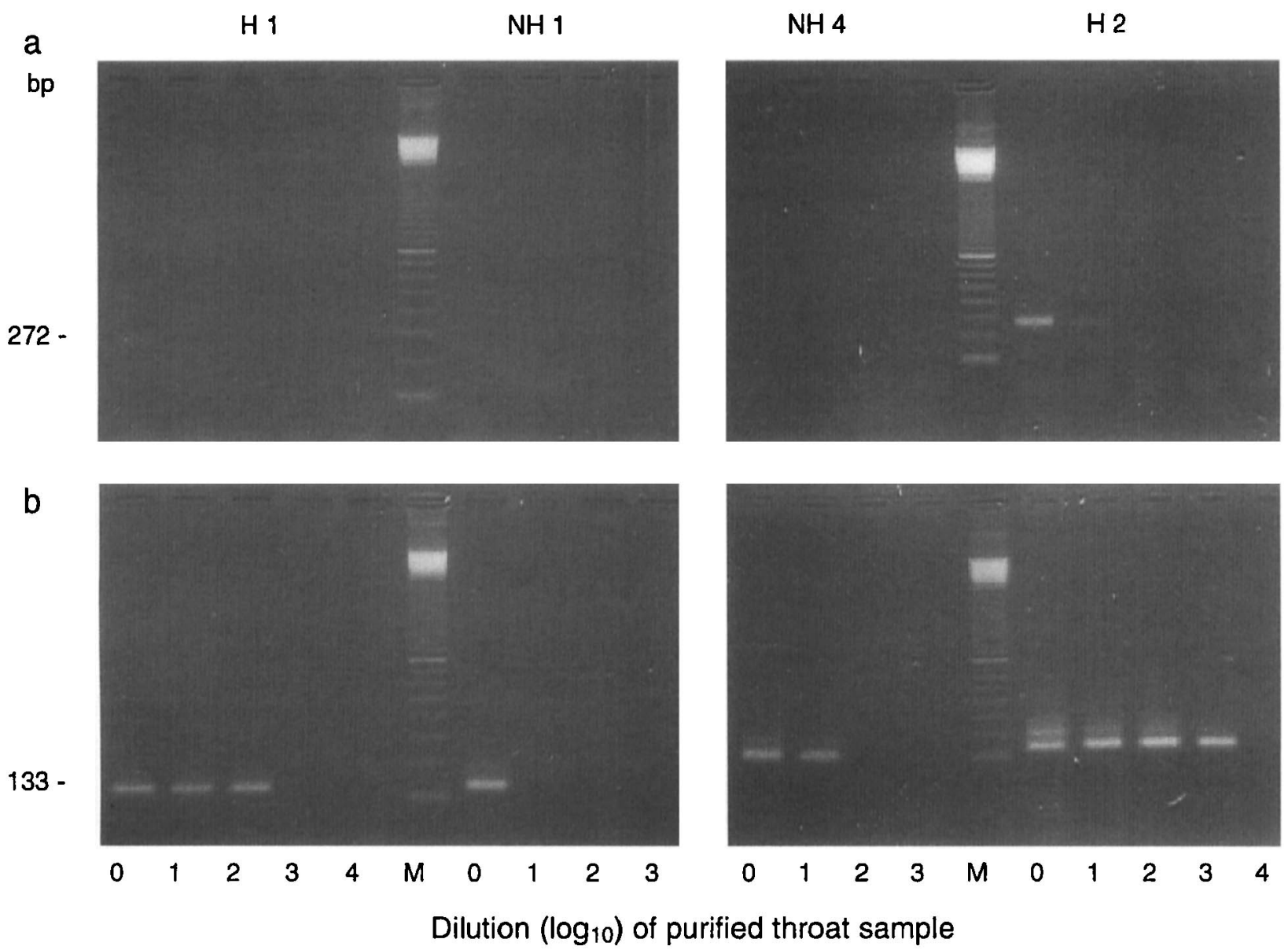

Fig. 2. Estimation of $M$. pneumoniae DNA in throat samples of four $M$. pneumoniae-positive patients. (a) First PCR; (b) second PCR. Serial 10-fold dilutions of a standard amount $(6.0 \mu \mathrm{g} / \mathrm{ml})$ of purified throat sample NA were subjected to the nested PCR. NH1 and NH4, non-hospitalised subjects with $M$. pneumoniae load of 33 and $170 \mathrm{cfu} / \mathrm{ml}$ throat sample respectively (NH1 was a GP patient and NH4 a symptomatic household contact). H1 and H2, hospitalised patients with $M$. pneumoniae load of 2500 and $3160 \mathrm{cfu} / \mathrm{ml}$ of throat sample, respectively. M, DNA mol. wt marker: 100 -bp ladder.

the nested PCR protocol consisting of a P1-1/P1-6 M. pneumoniae $\mathrm{Pl}$ gene PCR fragment, enlarged by insertion of a 210-bp E. coli lacZ fragment. The concentration of this $\mathrm{AC}$ is critical: it has to be sufficiently high to generate a visible amplification product and sufficiently low not to interfere with the detection of $M$. pneumoniae DNA due to competition. A carefully selected AC concentration of $0.07 \mathrm{fg} / \mu \mathrm{l}$ met both criteria (Fig. 1). As inhibition was found in $20 \%$ of the samples investigated, the inclusion of an $\mathrm{AC}$ for diagnostic application of this PCR is essential.

The frequency of $M$. pneumoniae infections in the different patient populations varied. The incidence of $M$. pneumoniae pneumonia among the patients hospitalised because of community-acquired pneumonia was $8 \%$, matching incidences reported by others in a nonepidemic situation [15]. In the population of patients visiting their GP because of a respiratory tract infection, the incidence of $M$. pneumoniae infection was lower (3\%). Among the household contacts of $M$. pneumoniae-positive patients the study found a rela- tively high percentage of $M$. pneumoniae PCR-positive subjects (13\%), indicating a high level of transmission in the household setting.

It has been recognised that quantification of various infectious agents can have diagnostic and prognostic implications. This may also be the case for $M$. pneumoniae. Estimation of the $M$. pneumoniae load by amplification techniques might be a valuable approach to distinguish between $M$. pneumoniae carriers and patients with a clinically significant infection. In contrast to blood, plasma or serum specimens, which are used for the quantification of mostly viral nucleic acids [29-31], throat swabs are subject to variation in their composition. Therefore, a semi-quantitative approach, rather than a quantitative PCR, was developed to estimate the $M$. pneumoniae load. The nested PCR was applied to a dilution series of purified NA from throat swab samples and it was found that the $M$. pneumoniae load in five hospitalised patients was significantly higher than in four nonhospitalised subjects. As the interval between the 


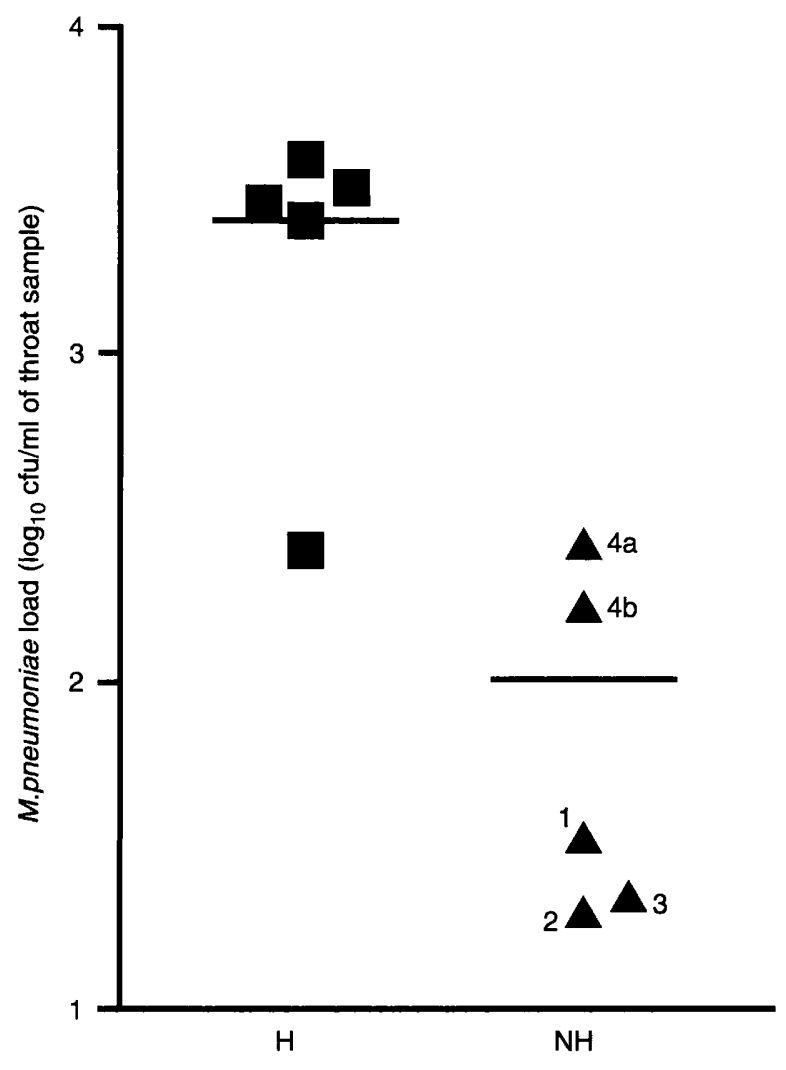

Fig. 3. The calculated number of cfu of $M$. pneumoniae based on semi-quantitative assessment by PCR in five $M$. pneumoniae-positive throat samples from five hospitalised patients $(\mathrm{H})$ and in five samples from four nonhospitalised subjects $(\mathrm{NH} 1-4)$. $\mathrm{NH} 1$ and $\mathrm{NH} 2$ were GP patients, NH3 was a household contact without symptoms and NH4 was a household contact first sampled when he was asymptomatic (4a), and 3 weeks later, when he had symptoms of a respiratory infection (4b). Bars represent mean numbers of $\mathrm{cfu}$.

occurrence of respiratory tract infection and the time of throat sampling and the mean age was similar in the hospitalised and non-hospitalised groups, this finding suggests that more severe respiratory tract infection due to $M$. pneumoniae is associated with higher loads of $M$. pneumoniae in the throat. These results are in accordance with those of two other studies, in which the M. pneumoniae load was assessed in a semiquantitative way in throat specimens from symptomatic patients and asymptomatic controls. Kleemola et al. used a commercial probe test during an epidemic of $M$. pneumoniae infections among army conscripts, and observed that 32 patients with clinically significant infection had higher probe test values than five asymptomatic controls [8]. Skakni et al. used a semiquantitative PCR and reported high loads of $M$. pneumoniae in 8 of 10 patients with acute pneumonia, and low loads in four asymptomatic patients with chronic pulmonary disease, in three patients with cystic fibrosis and in two patients with acute asthma [13]. Although the total number of individuals studied is still small, the findings of the present study as well as those discussed above strongly suggest a relationship between M. pneumoniae load and severity of disease. The $M$. pneumoniae-positive subjects in the present study were identified in a population of 302 subjects. A very large number of subjects would have to be studied to obtain a larger group of $M$. pneumoniae-positive hospitalised, non-hospitalised and asymptomatic persons.

In summary, a nested PCR protocol which allows the rapid, sensitive and specific detection of $M$. pneumoniae and the estimation of $M$. pneumoniae DNA load in throat swabs has been developed. With this method, a relationship between $M$. pneumoniae load in the throat and severity of disease was observed in a group of hospitalised patients, non-hospitalised patients and asymptomatic carriers.

We thank Dr D. Ursi, Dr M. Ieven and Professor H. Goossens, University Hospital Antwerpen, Belgium, for instruction regarding their routine PCR. This work was partially financially supported by Pfizer, The Netherlands.

This study was presented in part at the 36th Interscience Conference on Antimicrobial Agents and Chemotherapy (ICAAC, 1996) in New Orleans, LA, USA.

\section{References}

1. Clyde WA. Clinical overview of typical Mycoplasma pneumoniae infections. Clin Infect Dis 1993; 17 Suppl 1: S32-S36.

2. Meseguer MA, Garcia-Rull S, Picher J, Ortiz-Saracho J, Maiz L, Baquero F. Isolation of Mycoplasma pneumoniae from pericardial tissue. Eur J Clin Microbiol Infect Dis 1995; 14: $825-826$.

3. Narita M, Matsuzono Y, Togashi T, Kajii N. DNA diagnosis of central nervous system infection by Mycoplasma pneumoniae. Pediatrics 1992; 90: 250-253.

4. Dorigo-Zetsma JW, Zaat SAJ, Wertheim-van Dillen PME et al. Comparison of PCR, culture, and serological tests for diagnosis of Mycoplasma pneumoniae respiratory tract infection in children. J Clin Microbiol 1999; 37: 14-17.

5. Buck GE, O'Hara LC, Summersgill JT. Rapid, sensitive detection of Mycoplasma pneumoniae in simulated clinical specimens by DNA amplification. J Clin Microbiol 1992; 30: 3280-3283.

6. Dular R, Kajioka R, Kasatiya S. Comparison of Gen-Probe commercial kit and culture technique for the diagnosis of Mycoplasma pneumoniae infection. J Clin Microbiol 1988; 26: 1068-1069.

7. Hyman HC, Yogev D, Razin S. DNA probes for detection and identification of Mycoplasma pneumoniae and Mycoplasma genitalium. J Clin Microbiol 1987; 25: 726-728.

8. Kleemola SRM, Karjalainen JE, Räty RKH. Rapid diagnosis of Mycoplasma pneumoniae infection: clinical evaluation of a commercial probe test. $J$ Infect Dis 1990; 162: 70-75.

9. de Barbeyrac B, Bernet-Poggi C, Febrer F, Renaudin H, Dupon $\mathrm{M}$, Bebear C. Detection of Mycoplasma pneumoniae and Mycoplasma genitalium in clinical samples by polymerase chain reaction. Clin Infect Dis 1993; 17 Suppl 1: S83-S89.

10. Ieven M, Ursi D, Van Bever H, Quint W, Niesters HGM, Goossens $\mathrm{H}$. The detection of Mycoplasma pneumoniae by two polymerase chain reactions and role of $M$. pneumoniae in acute respiratory tract infections in pediatric patients. $J$ Infect Dis 1996; 173: 1445-1452.

11. van Kuppeveld FJ, Johansson KE, Galama JM et al. 16S rRNA based polymerase chain reaction compared with culture and serological methods for diagnosis of Mycoplasma pneumoniae infection. Eur J Clin Microbiol Infect Dis 1994; 13: 401-405.

12. Lüneberg E, Jensen JS, Frosch M. Detection of Mycoplasma pneumoniae by polymerase chain reaction and nonradioactive 
hybridization in microtiter plates. $J$ Clin Microbiol 1993; 31: 1088-1094.

13. Skakni L, Sardet A, Just $\mathbf{J}$ et al. Detection of Mycoplasma pneumoniae in clinical samples from pediatric patients by polymerase chain reaction. $J$ Clin Microbiol 1992; 30: $2638-2643$.

14. Tjhie JHT, van Kuppeveld FJM, Roosendaal $\mathrm{R}$ et al. Direct PCR enables detection of Mycoplasma pneumoniae in patients with respiratory tract infections. $J$ Clin Microbiol 1994; 32: 11-16.

15. Foy HM. Infections caused by Mycoplasma pneumoniae and possible carrier state in different populations of patients. Clin Infect Dis 1993; 17 Suppl 1: S37-S46.

16. Boom R, Sol CJA, Salimans MMM, Jansen CL, Wertheim-van Dillen PME, van der Noordaa J. Rapid and simple method for purification of nucleic acids. J Clin Microbiol 1990; 28: 495-503.

17. Dorigo-Zetsma JW, Zaat SAJ, Ursi D, Dankert J. Quantification of Mycoplasma pneumoniae in simulated clinical specimens using a nested polymerase chain reaction. IOM Letters 1994; 3: 496.

18. Ursi J-P, Ursi D, Ieven M, Pattyn SR. Utility of an internal control for the polymerase chain reaction. Application to detection of Mycoplasma pneumoniae in clinical specimens. APMIS 1992; 100: 635-639.

19. Su CJ, Tryon VV, Baseman JB. Cloning and sequence analysis of cytadhesin P1 gene from Mycoplasma pneumoniae. Infect Immun 1987; 55: 3023-3029.

20. Herrero M, de Lorenzo V, Timmis KN. Transposon vectors containing non-antibiotic resistance selection markers for cloning and stable chromosomal insertion of foreign genes in gram-negative bacteria. $J$ Bacteriol 1990; 172: 6557-6567.

21. Sambrook J, Fritsch EF, Maniatis T. In: Molecular cloning: a laboratory manual, 2nd edn. Cold Spring Harbor, NY, Cold Spring Harbor Laboratory Press. 1989.

22. Spaink HP, Okker RJH, Wijffelman CA, Pees E, Lugtenberg BJJ. Promotors in the modulation region of the Rhizobium leguminisarum Sym plasmid pRL1JI. Plant Mol Biol 1987; 9: 29-37.

23. Chanock RM, Mufson MA, James WD, Fox HH, Bloom HH, Forsyth B. Recovery of PPLO of atypical pneumoniae on artificial agar medium. Proc Soc Exp Biol Med 1962; 110: $543-547$.

24. Tully JG, Rose DL, Whitcomb RF, Wenzel RP. Enhanced isolation of Mycoplasma pneumoniae from throat washings with a newly modified culture medium. $J$ Infect Dis 1979; 139: $478-482$.

25. Leng Z, Kenny GE, Roberts MC. Evaluation of the detection limits of PCR for identification of Mycoplasma pneumoniae in clinical samples. Mol Cell Probes 1994; 8: 125-130.

26. Reznikov M, Blackmore TK, Finlay Jones JJ, Gordon DL. Comparison of nasopharyngeal aspirates and throat swab specimens in a polymerase chain reaction-based test for Mycoplasma pneumoniae. Eur J Clin Microbiol Infect Dis 1995; 14: $58-61$.

27. Williamson J, Marmion BP, Worswick DA et al. Laboratory diagnosis of Mycoplasma pneumoniae infection. 4. Antigen capture and PCR-gene amplification for detection of the mycoplasma: problems of clinical correlation. Epidemiol Infect 1992; 109: 519-537.

28. Jensen JS, Søndergård-Andersen J, Uldum SA, Lind K. Detection of Mycoplasma pneumoniae in simulated clinical samples by polymerase chain reaction. Brief report. APMIS 1989; 97: 1046-1048.

29. Fox JC, Griffiths PD, Emery VC. Quantification of human cytomegalovirus DNA using the polymerase chain reaction. $J$ Gen Virol 1992; 73: 2405-2408.

30. Piatak M, Luk KC, Williams B, Lifson JD. Quantitative competitive polymerase chain reaction for accurate quantitation of HIV DNA and RNA species. Biotechniques 1993; 14: $70-81$.

31. Secchiero P, Zella D, Crowley RW, Gallo RC, Lusso P. Quantitative PCR for human herpesviruses 6 and $7 . J$ Clin Microbiol 1995; 33: 2124-2130. 